\title{
Simulation on Three Dimensional Laminar Properties of Dew Point Evaporative Cooling in Plate Heat Exchanger
}

\author{
Pengfei Liu ${ }^{a}$, Xinyu $\mathrm{Li}^{\text {b }}$ \\ School of Mechanical Engineering, Tianjin Polytechnic University, Tianjin 300000, China \\ a975641358@qq.com, ${ }^{\text {b} X i n y u l i 7627 @ s i n a . c o m ~}$
}

Keywords: evaporative cooler of dew point; CFD and NHT; the numerical simulation of Fluent; the efficiency of dew point.

\begin{abstract}
This paper establishes the three dimensional laminar mathematical physical model of dew point evaporative cooling in plate heat exchanger, according to the simplifying assumptions of the complicated course for heat and mass transfer and counter-current flow in dew point evaporative cooler , using the CFD (computational fluid dynamics) and NHT (numerical heat transfer) method. By the numerical simulation of Fluent ANSYS, get the internal distribution of temperature field and concentration of water vapor field, and analyze the effects on dew point heat exchanger of perforation diameter, spacing and perforation mode which is set on the heat exchange plate between the dry and wet channel. The dew point efficiency of the optimized model and parameters approach to $71.2 \%$.
\end{abstract}

\section{Introduction}

With the advantages of more energy-saving and environmental protection, indirect evaporative cooling as a new kind of cooling mode at present, is getting more attention. Deal with reduction of air temperature ,but humidity remain unchanged. While, the way only treats air to the wet bulb temperature, and does not meet the demand of indoor thermal comfort. The technology of dew point cooling can cool fluid down to the wet bulb temperature that near the dew point temperature.

Yuan yijun invented multistage and regeneration of multi-channel cooling method and its heat exchanger [1].Yin jinfu used the wet energy through the method of multistage indirect evaporative cooling, and realized the wet bulb efficiency more than 100\%, and reduced the energy consumption [2]. Cui Jinju also did some experiment research on dew point indirect evaporative cooling [5], established a counter-current test-bed, calculated influence of factor such as the air flow rate, inlet air temperature, humidity, water quantities etc on the properties of dew point cooler. B.R angvilaiku1 and S. Kumar ,Asian institute of technology, did a lot of experimental research on dew point indirect evaporative cooling equipment the experimental results show that the wet bulb efficiency can reached $122 \%$, and the dew point efficiency got $85 \%$ [8] [9].

\section{The mathematical model of dew point cooler}

\subsection{The geometric description of the model}

In order to achieve the expected heat exchange capacity, Pro/E which is a $3 \mathrm{~d}$ model software and Fluent which is a simulation software are used to construct and calculate the dew point cooler. As shown in fig 1, the dew point cooler unit is divided into three channels, and its geometrical parameters is as shown in tab1.

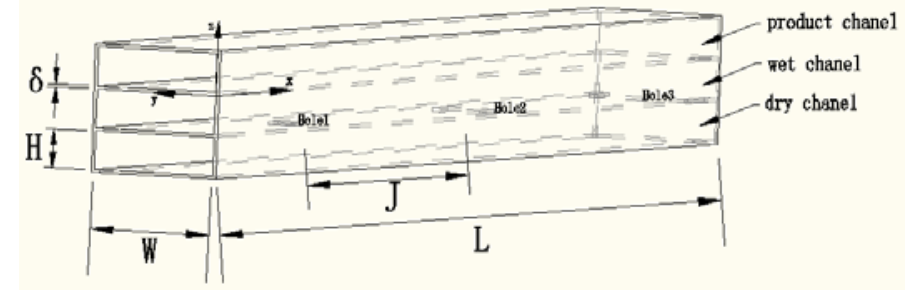

Fig.1 Three dimensional model of dew point evaporative cooler by PROE5.0 
Tab.1 Geometry of dew point evaporative cooler

\begin{tabular}{ccc}
\hline name & symbol & value \\
\hline Model Length & $\mathrm{L}$ & $200 \mathrm{~mm}$ \\
Model Width & $\mathrm{W}$ & $10 \mathrm{~mm}$ \\
Model Height & $\mathrm{H}$ & $3 \mathrm{~mm}$ \\
clapboard thickness & $\delta$ & $0.25 \mathrm{~mm}$ \\
First hole size & hole1 & $2 \times 2 \mathrm{~mm}^{2}$ \\
second hole size & hole2 & $3 \times 4 \mathrm{~mm}^{2}$ \\
third hole size & hole3 & $4 \times 8 \mathrm{~mm}^{2}$ \\
Hole spacing & $\mathrm{J}$ & $60 \mathrm{~mm}$ \\
\hline
\end{tabular}

The work process of the studied dew point evaporative cooling in plate heat exchanger is as shown in fig 2: dew point cooler is consisted of working air channel and output channel, and the working air channel that has a reverse flow as the arrows in fig2 is divided into interconnected dry channels (i.e, the primary air channel) and wet channels (i.e, the secondary air channel) by heat partition on which the holes are set. Because of the effect of a certain amount of spray water in the wet channel, water film is formed on the partition wall, that the heat transfer and mass exchange are caused by difference of temperature and water vapor concentration. Without the spray water, the side of the dry channel just has the heat transfer. And the coupled heat transfer is generated through the partition between the output channel and the wet channel. As fig3 shows, that the wet bulb temperature is decreased continuously until the dew point temperature by the technology of the dew point indirect evaporative cooling.

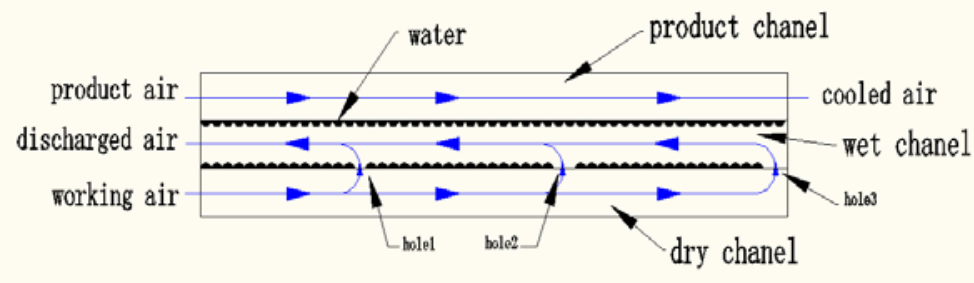

Fig.2 The working schematic diagram of dew point cooler

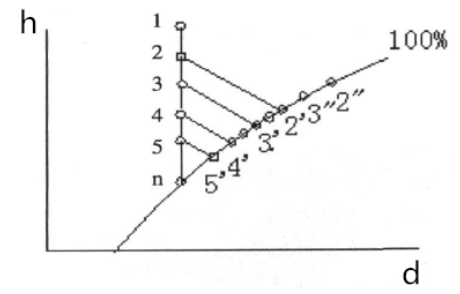

Fig.3 The principle of dew point indirect evaporative cooling technology

On account of the absorption of latent heat of vaporization by water-pellicle, the mechanism of heat and mass transfer becomes complicated relatively. In order to establish the physical model, simplified as follows:

(1) The dew point cooler has no heat and mass exchange with the outside world;

(2) The fluid is Newton fluid and is steady state and incompressible;

(3) Regardless of heat effect of viscous dissipation;

(4) Water film is covering homogeneously;

(5) Ignore the thermal resistance in the heat plate.

\subsection{Physical control equation}

In the dew point cooler, the fluid flow and heat transfer process satisfy the basic physical rules such as the mass conservation, momentum conservation and energy conservation. As mass transfer is 
took place in wet channel, the component transport equation is need to be satisfied. It is concluded that the following control equation:

Continuity equation:

Momentum equation:

$$
\frac{\partial(\rho \mathrm{u})}{\partial x}+\frac{\partial(\rho \mathrm{v})}{\partial y}+\frac{\partial(\rho \mathrm{w})}{\partial z}=0
$$

$$
\begin{aligned}
& \operatorname{div}(\rho u U)=\operatorname{div}(\mu \operatorname{gradu})-\frac{\partial p}{\partial \mathrm{x}} \\
& \operatorname{div}(\rho v U)=\operatorname{div}(\mu \operatorname{grad} v)-\frac{\partial p}{\partial \mathrm{y}} \\
& \operatorname{div}(\rho w U)=\operatorname{div}(\mu \mathrm{grad} w)-\frac{\partial p}{\partial \mathrm{z}}
\end{aligned}
$$

$\rho$-density of moist air; $\quad p$-Pressure, $p a$;

$u, v, w-x, y, z$ velocity components. $\quad \mu$-dynamic viscosity, $\mathrm{kg} /(\mathrm{m} \bullet \mathrm{s})$.

Energy equation:

$$
\begin{aligned}
& \frac{\partial(\rho u h)}{\partial x}+\frac{\partial(\rho v h)}{\partial y}+\frac{\partial(\rho w h)}{\partial z}= \\
& \operatorname{div}(\lambda \operatorname{grad} T)+\Phi+S_{h} \\
& \lambda \text {-thermal conductivity; } \\
& S_{h} \text { - energy source term. }
\end{aligned}
$$

Component transport equation:

$$
\begin{aligned}
& \frac{\partial\left(\rho u Y_{i}\right)}{\partial x}+\frac{\partial\left(\rho v Y_{i}\right)}{\partial y}+\frac{\partial\left(\rho w Y_{i}\right)}{\partial z}= \\
& -\frac{\partial}{\partial x}\left(D \frac{\partial Y_{i}}{\partial x}\right)-\frac{\partial}{\partial y}\left(D \frac{\partial Y_{i}}{\partial y}\right)-\frac{\partial}{\partial z}\left(D \frac{\partial Y_{i}}{\partial z}\right) \\
& Y \text {-mass fraction of water vapor; }
\end{aligned}
$$

\section{Simulation and analysis of the results}

\subsection{Finite element mesh}

MESH functional modules in the CFD software ANSYS14.5 is used in this article to grid the finite element, as shown in fig 4.

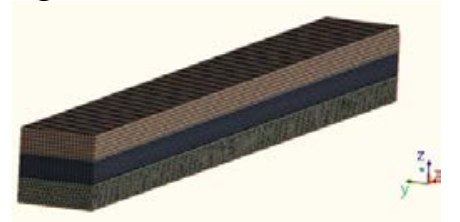

Fig4 Meshing under the circumstances of Ansys

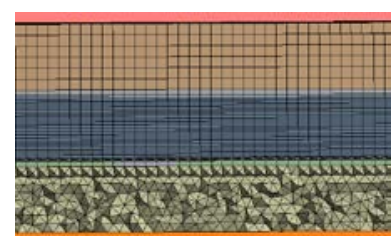

Fig.5 Local polyhedron grid in flow field

Pro/E5.0 is applied to construct the model, and save model files as the compatible STP format. Then split the flow field into more domains, especially dividing water film domain scrupulously.Establish the polyhedron grid and congest the grid of the secondary channel under the circumstances of Ansys MESH as fig5 shown. The model has been divided into 387452 units which are the tetrahedron and hexahedron mesh grid.

\subsection{Settings of the simulation}

Read in the 3d mesh under Fluent14.5 running environment, and set the gas density, viscosity and thermal conductivity, and compile the UDF command.. The specific data is shown in tab 2.

Tab.2 Dew point evaporative cooler simulation parameters

\begin{tabular}{ccc}
\hline name & symbol & valve \\
\hline inlet dry bulb temperature of Work air & $T_{p i}$ & $35{ }^{0} \mathrm{C}$ \\
Inlet velocity of Work air & $V_{p i}$ & $2 \mathrm{~m} / \mathrm{s}$ \\
relative humidity of Work air & $\varphi$ & $44 \%$ \\
inlet dry bulb temperature of output air & $T_{s i}$ & $35{ }^{0} \mathrm{C}$ \\
Inlet velocity of output air & $V_{s i}$ & $2 \mathrm{~m} / \mathrm{s}$ \\
Coefficient of latent heat of vaporization & $h_{m}$ & $2051 \mathrm{KJ} / \mathrm{KG}$ \\
Coefficient of Water vapor diffusion & $D$ & $0.22 \times 10 \mathrm{e}-4 \mathrm{~m} 2 / \mathrm{s}$ \\
\hline
\end{tabular}




\begin{tabular}{ccc}
\hline energy source term & Energy & UDF_source \\
saturated vapor mass fraction & Ho2 & UDF_fraction \\
\hline
\end{tabular}

\subsection{Analysis of the results}

As is shown in Fig6, the distribution of temperature field on $\mathrm{Y}=5 \mathrm{~mm}$ cut surface, the air temperature present the highest valve at the inlet of dry and output channel and present the lowest valve at the inlet of wet channel and outlet of output channel .
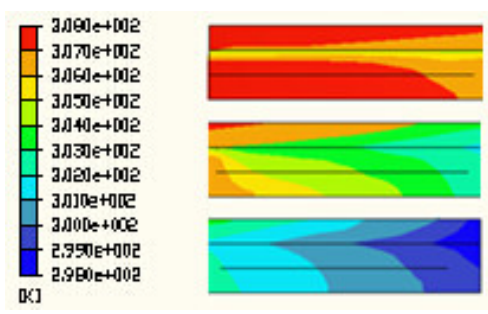

Fig.6 Temperature on $\mathrm{Y}=5 \mathrm{~mm}$ cut surface
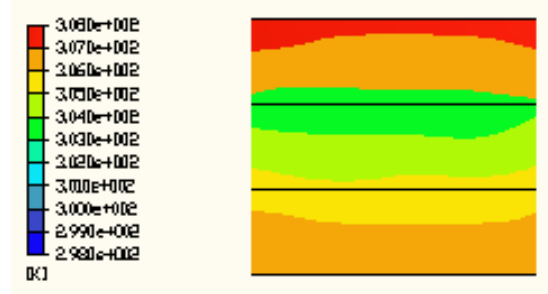

Fig.7 Temperature on $\mathrm{X}=70 \mathrm{~mm}$ cross section

As is shown in Fig7, it can be seen that the air temperature near the heat clapboard is lower than temperature in the central of the channel. It is because that the water-pellicle makes the temperature depressed on surface layer of the heat clapboard.

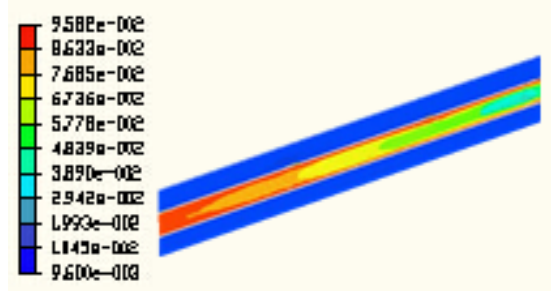

Fig.8 Mass concentration of water vapor on $\mathrm{Y}=5 \mathrm{~mm}$ cut surface

As is shown in Fig8, the mass concentration of water vapor is unchanged in output and dry channel. Due to the evaporation of water film, the mass concentration in the wet channel is getting increased along the flow direction.
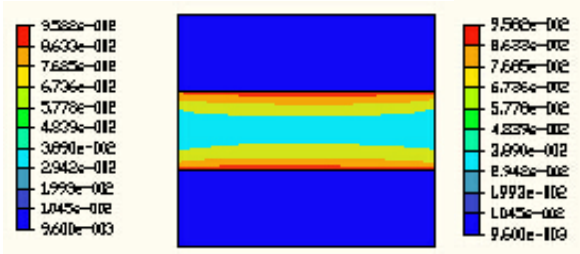

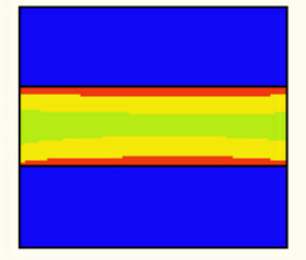

B Middle of wet channel
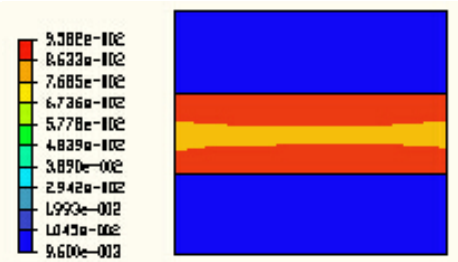

C close to outlet of wet channel

Fig.9 Mass concentration of water vapor on more sections

A, B, C in fig 9 illustrate the changing process of water vapor mass concentration. It can be seen from A, near the inlet of wet channel, the partial pressure of water vapor is high, so that the evaporation is strong. As can be seen from B and C, with the air flowing and the evaporation of the water film which cause the accumulation of water vapor increased, the gradient of mass concentration is got down, in return ,leading to rate of evaporation of the water film slow down, the vapor concentration becoming saturated gradually. The mass concentration of water vapor in the center of the wet channel is lower than it near the water film on the plate surface.

\subsection{Factors of the cooling effectiveness}

According to the principle of dew point evaporative cooling, the driving force of dew point evaporative cooling is the difference between dry bulb temperature of the primary air and the constant reduce of wet bulb temperature of the secondary air. The lower the temperature of secondary air, the better the effect of heat transfer with output air. The efficiency of dew point cooler can be defined as:

$$
\eta_{d p}=\frac{T_{i}-T_{0}}{T_{i}-T_{i . d p}}
$$

$T_{i}$ —dry bulb temperature of inlet, $\mathrm{K} ; T_{o}$ — dry bulb temperature of outlet, K; 


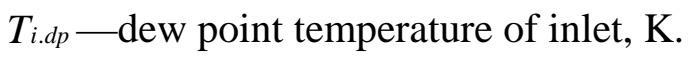

Compare the influence on dew point cooler with two different ways of perforation mode that perforation diameter is changed with hole spacing.

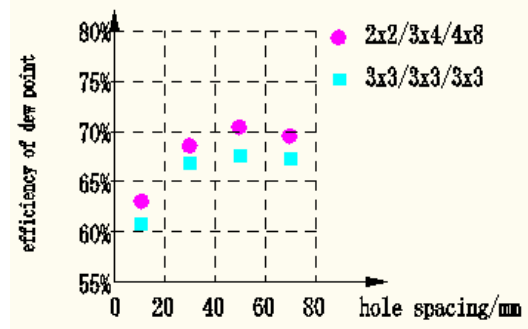

Fig.10 Influence on dew point cooler of hole opening and spacing way

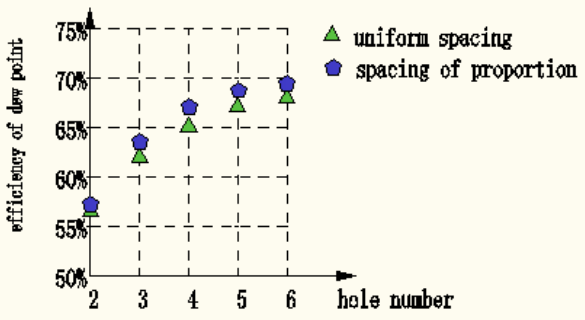

Fig.11 Influence on dew point cooler of hole way of equal space and scaled distance

As is shown in fig10, the dew point efficiency of the way $2 \times 2 / 3 \times 4 / 4 x 8$ is higher than the way $3 \times 3 / 3 \times 3 / 3 x 3$. That the hole spacing is too large or too small does not good to heat transfer of the dew point cooler, the hole spacing between 50 and $70 \mathrm{~mm}$ that can realize much higher the efficiency of the dew point. As is shown in fig11, under the scope of the selected number of the perforation, the dew point efficiency of whole spacing by a certain proportion is slightly higher than the way by the uniform spacing of perforation, that makes less sense on heat transfer of the dew point cooler.

\section{Summary}

From the above simulation results, the plate perforation diameter, spacing and perforation mode have great influence on the efficiency of the cooler. If the whole diameter changes with the increase of whole spacing, the better effect of dew point cooler will be.

In this paper, the dew point efficiency of the optimized model and simulation approach to reach71.2\%, nearly 15\% lower than the literature [11].The reasons for the disparity are that, the simulation in the paper do has some simplification and assumption, that make the boundary conditions and the actual situation different, but it makes much sense to theoretical guidance of the variation tendency of internal field in the dew point cooler. Because of restriction of time and working conditions, this paper just puts a single unit into simulation. The coupled simulation of multiple functional units and the realize of the multilevel utilization of dew-point cooling still need the follow-up work and more further study by the subsequent scholars.

\section{References}

[1] Yuan YiJun,Zhou Deng Li.Multistage Regenerative and Multi-channel Evaporative Cooling Method and Heat Exchanger[P], 2003.

[2] Yi JinFu,A Single and Multi-stage Indirect Evaporative Cooling Method on the Recycled Use of Wet Energy[P], 2005.

[3] Zhao ZhenSheng,Improved Experimental Study and Simulation on CFD Models of an Indirect Evaporative Cooler[D].Hunan:Hunan University,2010 
[4] Zhang Qing,HaoYuTao,Yang Shuang, etal.Research Progress and Present Situation Analysis of Dew Point Indirect Evaporative Cooling Technology[J]. Refrigeration \& Air-Conditioning, $2010(01)$

[5] Cui JinJu,Liu ZhongBao,Design and Experimental Research on a Counter-current Dew Point Indirect Evaporative Cooler [J],China Appliance Technology,2012 (3): 68-70.

[6] Pescod D. A heat exchanger for energy saving in an air-conditioning plant [J]. ASHRAE Transactions, 1979, 85(2): 238-251.

[7] Maisotsenko V, Gillan L.Maisotsenko cycle for air desiccant cooling[C]

[8] B.Riangvilaikul, S.Kumar. An experimental study of an over dew point evaporative cooling system: Energy-and Building.42 (2010)63 7-644.

[9] B.Riangvilaikul ,S.Kumar. Numerical study of a novel dew point evaporative cooling system [J].Energy and Buildings, 2010, 42(11):2241-2250. 